\title{
UNIVERSITYOF
}

FORWARD

THINKING

WESTMINSTER用

WestminsterResearch

http://www.westminster.ac.uk/westminsterresearch

Designing Momentums: Site, Practice, Media as Landscape

Geros, C.

This is the peer reviewed version of the following article: Geros, C. 2020. Designing Momentums: Site, Practice, Media as Landscape. Architectural Design. 90 (1), pp. 1421, doi.org/10.1002/ad.2520, which has been published in final form at:

https://doi.org/10.1002/ad.2520.

This article may be used for non-commercial purposes in accordance with Wiley Terms and Conditions for Self-Archiving.

The WestminsterResearch online digital archive at the University of Westminster aims to make the research output of the University available to a wider audience. Copyright and Moral Rights remain with the authors and/or copyright owners. 


\section{Designing Momentums Site, Practice, Media as Landscape}

To be concerned with and about the environment is to imagine a practice of being and a way of seeing, inhabiting and designing momentums. Landscape architecture is well positioned to explore environmental concerns by de-centering the human through an expanded acknowledgment of shifting relationships to others and their transformations. In the context of two current design-led research projects - The Orang-orang and the Hutan, within the Royal College of Art's MA Environmental Architecture Programme; and Monsoon Assemblages, led by Lindsay Bremner at the University of Westminster, both in London - the place of the designer and the moment of design are reimagined in the search for knowledge, its formation and infrastructure. ${ }^{1}$ At the core of both projects, landscape architecture is considered as an ecology of practice which aims to address questions of who is designing, with whom and to what end. Each project begins from an understanding that 'landscape' is no longer a-thing-out-of, nor is it a-space-within our built environments; rather, we are landscape our thoughts, actions and inactions enmeshed within ecologies. Engaged in both 'field' and archival research, each project aims to build itself from within conversations, drawing out questions that offer opportunities for realignment and growth able to produce material and political change capable of mobilising energies, human and nonhuman, into action.

To begin, it is necessary to provide some contextual framework for the practice of landscape architecture, as both projects are multidisciplinary. To accommodate the identification of 'landscape as site' and the emergence of 'landscape as practice' within different conceptual frameworks, both projects acknowledge landscape as both a territory of human-ecological entanglements and as a means to uncover and engage with sources of degradation and renewal. Additionally, both projects are long-term applied research endeavours and, as such, are in-progress - continually redefining both objectives and methods as they mediate between 'field' and 'archive'.

\section{Landscape as Site}

Borneo, in particular the carbon-rich soils that construct the biologically diverse ecosystems of the tropical peatland, as a site of investigation and intervention requires human activity to be addressed within geological processes of accumulation and extraction. The natural structure of the peat bog provides deep pockets of oxygenated organic matter that produces long, smouldering fires. These fires restructure soil nutrients and waterholding capacities into more stable matter capable of a full index of fertility. 
Over thousands of years these assemblages of human-forest relations, or anthrosols, have transformed pockets of nutrient-poor soils into highly productive lands. The 'site' of The Orang-orang and the Hutan transcends the surface, engaging with micro-characteristics produced by and productive of human activity.

05_Yu_Central Kalimantan_2019.tiff

An architect of time and space around the globe, the monsoon constructs ecologies, customs and cultures - environments - within and across landscapes. Itself an assembling of earth-system dynamics, it is experienced differently, at different scales, around the globe; yet has become synonymous with South Asia. Focused around the Bay of Bengal from Chennai, India to Dhaka, Bangladesh and Yangon, Myanmar Monsoon Assemblages engages with the 'site' of the monsoon as both a material and cultural construct embedded within social environments, both human and nonhuman.

Acknowledging that landscape is more than land, requires a shift in focus. The terms 'land' and 'landscape' carry connotations of the natural, the aesthetic and the agricultural along with histories of legal and territorial ideas of national politics and cultural identities. As Kenneth Olwig suggests, 'customs and culture defined a Land, not physical geographical characteristics'; ${ }^{2}$ thus, landscape is not bound to land, but is held within an environment.

\section{Landscape as Practice}

A situated understanding of landscape as a moment within and amongst environments - a constellation of relational consistencies of coexistence bears in mind that any landscape must be horizenless, ever evolving, and always becoming. Approaching this as a site of investigation necessitates an expanding field of practices which can be utilised within landscape architecture and considered 'a tool for thinking through what is happening'. ${ }^{3}$ For centuries, the spatial arts have operated as interrelated ways of articulating, sharing and shaping culture ${ }^{4}$ - performing as nonneutral tools for seeing and making. Working across disciplines and within ever-evolving 'sites', the interventive nature of design often finds itself in the articulation of questions which may mobilise momentums towards previously unimagined environments.

Monsoon Assemblages is a five-year research project funded by the European Research Council (ERC) under the European Union's Horizon 2020 research and innovation programme (Grant Agreement No. 679873) and begun in 2016. While multidisciplinary, it is a design-led project that focuses a critical lens on established and changing relationships between the people, lands and cities of the monsoon through novel approaches to materialisms, cartographies and narratives. In the 'field', photography, film, 
drawing and interviews are used to uncover ways of knowing and living with the monsoon that may elude mainstream narratives. Often these techniques capture large- and small-scale narratives that present challenges inherent to processes of combining qualitative and quantitative data of different timescales and mediums - yet are essential to drawing out changing relations to staid notions of climate. For example, with the Bede or 'river gypsies' - of Louhajong, Bangladesh, conversations with individuals quickly grew to large, animated meetings with the community and a drawing of a 'monsoon calendar' constructed around patterns of seasonal movement timed with river allowances afforded by monsoonal flows from the Tibetan Plateau. Upon return to London, these accounts try to find resolution within the 'archive' of monsoonal time and space.

\section{0_Geros_Louhajong_Bangladesh_2018.tiff}

The Orang-orang and the Hutan began in 2019 as a four-year studio research project. Framed within the academic studio, it engages design students with local environmental activists, geographers, farmers, filmmakers and researchers in Borneo to address trans-scalar concerns, from the soils that bear them to the airs that carry them. Born from extractive agricultural practices, conflicts over indigenous lands and rights of inhabitation converge through knowledge and production of soils. In the 'field', students work in collaboration with residents - of different genders, ages, occupations and land tenures - to uncover knowledge about these soils, passed from person to person, generation to generation, that may offer material proof of occupation. On a recent trip to Mantangai in Central Kalimantan, residents and students used drones to follow a centuries-old boundary between one village and another. Once marked by the periodic placement of vertical posts, the acidic waters of the peat swamp had dissolved evidence of the path's intentional placement; yet seen from the air, the path's dimensions and geometry - a clear departure from its surroundings - could clearly be traced. This boundary was not a marker of property, but of soil knowledge - each side of the line productive of a particular crop - proof of cohabitation and soil production long preceding the government's claim to land. In the studio, students continue to collaborate with their co-conspirators in Borneo to find ways to map this knowledge and construct an authoritative 'archive' of the unseen and erased.

04_Yu_Mantangai_2019.tiff

09_Geros_Mantangai_2019.tiff

\section{Ecologies of Medias}

Expanding landscape 'site' and 'practice' also questions the medium and collaboration of design. Monsoon Assemblages and The Orang-orang and 
the Hutan both propose 'sites' that are cultural and institutional constructions of social and scientific media. Both projects aim to be interventive and impactful, while driven by process and not geared towards solutionist propositions and final outputs; but what does that mean for design? Towards design imaginaries for projects that are in progress, it is useful to engage with another project that probes 'site' and 'practice', allowing a process of engagement to perform as 'media' and 'collaboration' that is generative towards landscape and design.

Lying within monsoonal territory and home to more than 30 million residents, built atop a deltaic plain traversed by 13 rivers, Jakarta, Indonesia is affected by regular and significant flooding. However, in a tangle of concrete roadways and high-rise buildings, the river network - the actual pumping heart of the city - is often obscured from view and unable to mediate the city's inundation. Working across disciplines including design, geography, computer science and philosophy, and employing a diverse set of methods for research, PetaBencana.id has created an online monitoring and coordination platform that allows residents to help one another during flood events. ${ }^{5}$ Based on ethnographic research, the design of the platform learns from the residents of the city and expands the already existing epistemological network of river knowledge into an online geospatial conversation - publicly built and accessible - drawing the river back into the city's consciousness. Inhabiting the riverbanks and bearing the highest levels of risk, the city's urban poor acknowledge a 'belonging' with the river; while the city's more affluent residents often neglect to recognise themselves as sharing the same urban ecology. In mapping conversations about flooding, the resultant image draws the river and the city together into shared belonging and shared care.

01_Geros_Waduk Pluit_Jakarta_2015.tiff

02_Geros_Ciliwung River_Jakarta_2017.tiff

03_Holderness_petajakarta_2014.tiff

Like PetaBencana.id, Monsoon Assemblages and The Orang-orang and the Hutan work between the 'field' and the 'archive' to create media that enable a continued learning process - a collaboration - with their environments. Beyond illustrative imaging, these new constructions of knowledge aim to be instructive of new questions, new engagements and new momentums.

Archival research of the monsoon reveals an evolution of cartographic constructions since the 17th century. Processes of 'unfolding potential', these cartographies 'enable, rather than depict' the spaces and relationships of the monsoon through particular moments of social and institutional construction. ${ }^{6}$ Most often constructed as revenue-building infrastructure or weather-induced risk, today's changing monsoon now asks to be reconceived of as landscape - a moment of mediation between two horizons and a site within which the built environment is entangled. From policy to design, the enabled imaginary of a kinetic site is a question of 
landscape architecture at the very edges of its practice. How might the world appear through the lens of the monsoon?

08 Cook Monsoon Assemblages Section Through the Subcontinental Monsoon_2019.tiff

07_Geros_Monsoon Assemblages_The Global Monsoon_2019.tiff

By contrast, the soils of the Bornean peatland lack representation and their terra-nullius status constructs their vulnerability. Exposing the epistemological frameworks that have produced these soils through centuries of cohabitation, may enable these soils to voice themselves within their environments. Detailed knowledge of specific plant species, the colour of the smoke released from burning grounds and the response of soil to the sole of a boot can build an atlas of knowledge about the horizontal and vertical dimensions of a peat bog. The generation of media to collect, collate and represent this knowledge has the potential to intercede within the current crisis produced by the industrial commodification of underrepresented soils. From hyper-micro to extra-macro, the human and nonhuman actors constituent within the local and global reach of this environment must be considered as designers of a landscape. In the performance of due diligence, shouldn't one ask: What is the cost of one cubic hectare of carbon? And who will pay the price?

11_Yu_Discrepant Cartography_2019.tiff - DESIGNER NB: USE VERY LARG $\overline{\mathrm{R}}$

\section{Medias of Landscape}

Whether representing existing epistemologies or attempting to weave themselves into these networks, both projects aim to produce new ontologies within shared neuro-ecological landscapes. As each participates in a hyper-sensed and recorded world, a continual process of engagement allows opportunities of material, political and social change to emerge through interactive landscapes. An active evolution of landscape architecture - always at the edge of bounded discipline - allows it to attend to shifting environments; while designing shifts through and towards engaged landscapes that place the environment as the object of concern and cooperation. As long-term engagements of interventive experiment addressing questions of environmental representation, these projects operate as disciplinary probes - processes of questioning and redefining partnerships and methods of design action.

Text ( 2020 John Wiley \& Sons Ltd. Images: ???? 


\section{Notes}

1. Christina Leigh Geros, Studio 2: The Orang-orang and the Hutan, Royal College of Art: https://www.rca.ac.uk/schools/school-of-architecture/environmentalarchitecture/studio-descriptors-201819/studio-2-orang-orang-and-hutan/; Lindsay Bremner, The Research Project, Monsoon Assemblages: http://www.monass.org/project/.

2. Kenneth Olwig, Landscape, Nature, and the Body Politic: From Britain's Renaissance to America's New World, University of Wisconsin Press, Madison (WI), 2002, p 19.

3. Isabelle Stengers, 'Introductory Notes on an Ecology of Practices', Cultural Studies Review, 11 (1), 2005.

4. David Leatherbarrow, 'Is Landscape Architecture?', in Gareth Doherty and Charles Waldheim (eds), Is Landscape ... ? Essays on the Identity of Landscape, Routledge (Oxford and New York), 2016, p 641.

5. Yayasan Peta Bencana, PetaBencana.id: Bersama Kurangi Risiko, PetaBencana.id, https://info.petabencana.id/about/.

6. James Corner, 'The Agency of Mapping', in Denis Cosgrove (ed), Mappings, Reaktion Books (London), 1999, pp 231-52.

\section{CAPTIONS}

\section{Yu Central Kalimantan 2019.tiff}

Kaiwen Yu, Discrepant Cartographies: Central Kalimantan, Borneo, Indonesia, The Orang-orang and the Hutan, MA Environmental Architecture, Royal College of Art (RCA), London, January 2019

Working with satellite imagery and GIS software, MA student Yu experimented with colour band combinations $(6,5$ and 2$)$ to expose patterns of active burn and historic char in the detection of fire activity in peatlands.

\section{0_Geros_Louhajong_Bangladesh_2018.tiff}

\section{Beth Cullen drawing monsoon calendars in Louhajong, Bangladesh, Monsoon Assemblages, University of Westminster, London, 2018}

In the 'field', Beth Cullen draws a version of a monsoon calendar as it emerges from conversations with the Bede community; while Christina Leigh Geros documents the process with video and photographic footage.

04_Yu_Mantangai_2019.tiff 
Kaiwen Yu, Discrepant Cartographies: Mantangai, Central Kalimantan, Borneo, Indonesia, The Orang-orang and the Hutan, MA Environmental Architecture, Royal College of Art, London, January 2019

Yu worked with local residents and environmental activists with Walhi in Central Kalimantan to begin mapping 'hidden' markers of indigenous land tracts using aerial footage enabled by drone imagery.

\section{Geros Waduk Pluit Jakarta 2015.tiff}

Christina Leigh Geros, The Cityness of Jakarta's Landscape, Jakarta, Indonesia, 2015

Waduk Pluit resides at the northern edge of the city, near the Jakarta Bay, and is indicative of the complexities of Jakarta's urban environment.

02_Geros_Ciliwung River_Jakarta_2017.tiff

Christina Leigh Geros, The Ciliwung River: Out of Sight, Out of Mind, Jakarta, Indonesia, 2017

The 'Project of Normalisation', which began in 2012, placed Jakarta's rivers behind concrete walls in an attempt to prevent flooding; instead of prevention, the inevitable floods became more unpredictable.

03_Holderness_petajakarta_2014.tiff

Tomas Holderness, Proof-of-Concept, PetaJakarta (PetaBencana.id), Jakarta, Indonesia, 2014

At the outset, the project team tested the efficacy of social media for flood communication. During the monsoon season of 2013-14, over 13 million tweets about flooding were logged in the greater metropolitan district of Jakarta.

08_Cook_Monsoon Assemblages_Section Through the Subcontinental Monsoon_2019.tiff

John Cook, Section Through the Subcontinental Monsoon, Monsoon Assemblages, University of Westminster, London, 2019

Taken along longitude 77.5 E and using mean data from June to August of 2016, this section through the subcontinental monsoon extends the landscape into the atmosphere. In a particular moment of shifting monsoon habitats, the sectional view experiments with addressing the kinetic landscape.

07_Geros_Monsoon Assemblages_The Global Monsoon_2019.tiff 
Christina Leigh Geros, The Global Monsoon, Monsoon Assemblages, University of Westminster, London, 2019

An experimental exploration of the cartographically constructed world through the annual cycles of the monsoon's atmospheric centres of action, produced through data and research of the monsoon that has been compiled since 1875. In its action, the monsoon brings only certain corners of the globe into focus.

06:

Kaiwen Yu, Architectural Diagram of Knowledge Infrastructure, The Orang-orang and the Hutan, MA Environmental Architecture, Royal College of Art, London, 2019

Yu diagrams existing and potential relationships between the landscape of Central Kalimantan and its residents to identify design opportunities within the production and communication of knowledge.

\section{$11 \mathrm{Yu}$ Discrepant Cartography 2019.tiff - DESIGNER NB: USE VERY LARGE}

Kaiwen Yu, Discrepant Cartographies, The Orang-orang and the Hutan, MA Environmental Architecture, Royal College of Art, London, 2019

Yu begins his investigation into the 'discrepant cartographies' of Borneo's peatlands - asking what can be seen, from what distance, with what 'eye', and what can be known from it?

\section{Geros Mantangai 2019.tiff}

Seeking remnants of lost boundaries in Mantangai, Central Kalimantan, Borneo, Indonesia, The Orang-orang and the Hutan, MA Environmental Architecture, Royal College of Art, London, January 2019

In the 'field' of Central Kalimantan, students explored the canals of Borneo's peatlands with environmental activists from Walhi and local residents, in search of methods of representation of nearly lost historical boundaries. 